\title{
INHIBITION OF SALMONELLA SEROVARS, ESCHERICHIA COLI 0157:H7 AND LISTERIA MONOCYTOGENES DURING DRY-CURING AND DRYING OF MEAT: A CASE STUDY WITH BASTURMA
}

\author{
${ }^{1}$ Department of Food Science \\ ${ }^{2}$ Department of Animal Sciences \\ University of Wisconsin-Madison \\ 1675 Observatory Dr. \\ Madison, WI 53706-1284
}

STEVEN C. INGHAM ${ }^{1,3}$, GINA SEARLS $^{2}$ and DENNIS R. BUEGE ${ }^{2}$

Accepted for Publication November 2, 2005

\begin{abstract}
Basturma, a spiced beef product intended to be cooked before consumption, was prepared in three trials by dry-curing intact surface-inoculated (6 log cfu per piece with Salmonella serovars, Escherichia coli O157:H7 and Listeria monocytogenes) beef eye of round subprimals for 21 days at $6.7 C$, and then rinsing, pressing and drying for 6-8 days at 21-27C. The finished products had percentage water-phase salt concentrations of 8.3-18.0 and water activity of 0.84-0.95. In the finished product, no surviving Salmonella serovars and E. coli O157:H7 were detected $(<1.0 \log$ cfu) in two trials; in the third trial the reductions were 4.5 and $5.0 \log c f u$, respectively. L. monocytogenes populations decreased 4.0-4.9 log cfu. Basturma prepared by dry-curing, rinsing, pressing and drying appears to present little risk of foodborne infection because this process reduces populations of Salmonella serovars, E. coli O157:H7 and L. monocytogenes. Dry-curing and drying are potentially very important pathogen-reduction steps.
\end{abstract}

\section{INTRODUCTION}

Dry-curing and drying steps are used in making a variety of specialty processed meats. In typical dry-curing, raw pieces of meat are rubbed or coated with a mixture containing sodium chloride, sodium nitrite and perhaps some proprietary spices. The meat pieces are then stored at a cold or moder-

${ }^{3}$ Corresponding author. TEL: (608) 265-4801; FAX: (608) 262-6872; EMAIL: scingham@ wisc.edu 
ately abusive temperature for a period of several days (Aberle et al. 2001). During this time, fluid is lost from the meat, and if the meat pieces are in a nondraining container, the fluid may coat most or all of the pieces (authors' unpublished observations). Drying procedures vary in terms of temperature, relative humidity $(\mathrm{RH})$, air movement and final product characteristics. Some products are dried at ambient temperatures, e.g., country ham, and others such as beef jerky are dried at elevated temperatures (Aberle et al. 2001). Little research has been performed on the potential for pathogen growth on meat products processed sequentially by dry-curing and ambient-temperature drying. However, an understanding of pathogen behavior during these steps is essential for the successful development of scientifically valid critical limits for hazard analysis critical control point (HACCP) plans.

This study originated from contact with a commercial processor producing basturma. Basturma (also spelled basterma, pasturma or pastirma) refers to a variety of meat products originating in Armenia and neighboring countries (Anon 2005a,b,c). However, in this study basturma refers to a product made from intact beef eye of round subprimals (hereafter referred to as rounds) that are dry-cured, rinsed, pressed and dried, with a spice paste coating added to impart flavor and color. The finished product is sold under refrigeration as a raw product; therefore, consumers are expected to cook the product before eating it. Basturma made by the usual process typically has a final water activity $\left(A_{\mathrm{w}}\right)$ of $0.80-0.85$, which is below the $A_{\mathrm{w}}$ commonly regarded as the lower limit for pathogenic bacterial growth (Jay 1992).

This commercial basturma product would likely be placed in the "raw product, not ground" category in the HACCP food safety system mandated by the U.S. Department of Agriculture (USDA 1996b). The authors have observed that the major critical control point (CCP) in commercial HACCP plans for products in this category is usually the step in the process at which the product is the warmest and therefore pathogen growth is most likely to occur. At each CCP identified, critical limits must be met to ensure control of significant hazards (USDA 1997). Two significant microbiological hazards associated with raw meat and poultry products are Salmonella serovars and Escherichia coli O157:H7 (USDA 1999a). Processors have limited control over whether these pathogens are present in the raw meat that they receive for processing. Therefore, processors making raw products must select a CCP and associated critical limits that will ensure no increase in risk results from the growth of pathogens in contaminated raw ingredients. Specifically, it is the authors' experience that regulatory officials expect processors of raw products to use CCP critical limits (time and temperature) that have been scientifically validated to prevent the growth of Salmonella serovars and E. coli O157:H7. Little has been reported on the growth of Salmonella serovars and E. coli O157:H7 on meat during sequential dry-curing and drying, so the first objective of this 
study was to evaluate growth of these pathogens during the basturma-making process used by the collaborating industry partner as a case study.

An additional microbiological hazard of potential concern in basturma is Listeria monocytogenes. Basturma is sold as a raw product, so cooking by the consumer is important for preventing listeriosis associated with this product. However, the authors believe that some consumers may be unfamiliar with basturma and eat it without first cooking it. A factor reducing the likelihood of listeriosis resulting from such mishandling is that L. monocytogenes growth on the finished product is unlikely because of its reduced $A_{\mathrm{w}}$. Guidance from the USDA states that decreasing a product's $A_{\mathrm{w}}$ to $<0.92$ will prevent $L$. monocytogenes growth (USDA 2004). However, it is not clear whether L. monocytogenes could grow during processing steps prior to the $A_{\mathrm{w}}$ falling below this level. Therefore, the second objective of this study was to evaluate the survival and/or growth of L. monocytogenes during the basturma-making process used by the collaborating industry partner.

\section{MATERIALS AND METHODS}

\section{Inoculum Preparation}

Five strains each of E. coli 0517:H7, Salmonella serovars and L. monocytogenes were used for inoculation. E. coli O157:H7 strains ATCC 43894, 51657 and 51658 (American Type Culture Collection, Manassas, VA) are clinical isolates; strain ATCC 43895 was from ground beef implicated in an outbreak; and strain USDA-FSIS-380-94 was originally isolated from salami linked to an illness outbreak and obtained from Dr. John Luchansky (Food Research Institute, University of Wisconsin-Madison, Madison, WI). Salmonella serovars used were Salmonella hadar S21, Salmonella typhimurium S9, Salmonella infantis S20, Salmonella anatum S14 and Salmonella heidelberg S13. All of the salmonellae were obtained from Dr. Eric Johnson (Food Research Institute, University of Wisconsin-Madison). The original source was unknown for strains S21 and S20, while strains S9, S13 and S14 were originally isolated from samples submitted to the Wisconsin State Laboratory of Hygiene. The L. monocytogenes strains used were all also obtained from the laboratory of Dr. Eric Johnson (Food Research Institute, University of Wisconsin-Madison) and were originally from an infected patient (Scott A), hard salami (101 and 108), goat cheese (310) and raw milk (V7). Stock cultures were maintained at -20C in brain-heart infusion broth (BHIB; Difco, Becton-Dickinson, Sparks, MD), with $10 \%$ (w/v) added glycerol (Fisher Scientific, Itasca, IL). Working cultures, maintained at $4 \mathrm{C}$ on brain-heart infusion agar (BHIA; Difco) were prepared monthly from frozen stock cultures. To 
obtain a working culture, a strain was cultured twice successively at $35 \mathrm{C}$ for 18-24 h in BHIB, streaked to a BHIA plate, incubated at 35C for $18-24 \mathrm{~h}$, examined for purity and then stored at $4 \mathrm{C}$. Inoculation cultures were prepared for each strain by transferring a loopful of growth from the working culture plate to $25 \mathrm{~mL}$ of BHIB and incubating at $35 \mathrm{C}$ for $20-24 \mathrm{~h}$. To prepare a five-strain inoculum cocktail of each organism, the BHIB culture of each organism was centrifuged for $12 \mathrm{~min}$ at $5000 \times \mathrm{g}$, the supernatant in each tube decanted and each pellet resuspended with approximately $2.5 \mathrm{~mL}$ of Butterfield's phosphate diluent (BPD; Nelson Jameson, Marshfield, WI), and then all five strains were combined. To prepare the final inoculum cocktail, all three cocktails were combined in one $50-\mathrm{mL}$ sterile plastic tube (Falcon brand, Fisher Scientific) and vortex mixed.

\section{Meat Product and Inoculation}

In each of three trials, 18 commercial rounds were used. Fresh rounds were received $24 \mathrm{~h}$ prior to inoculation and stored at approximately $5 \mathrm{C}$ until used. Rounds ranged from 1.81 to $2.72 \mathrm{~kg}$ with typical dimensions of $25.4 \times 12.7 \times 10.2 \mathrm{~cm}$. Rounds were not trimmed of external fat in trials 1 and 2 but were trimmed prior to inoculation procedures in trial 3. To inoculate each round, a $0.25-\mathrm{mL}$ volume of the undiluted cocktail (approximately $\log 9 \mathrm{cfu} /$ $\mathrm{mL}$ ) was pipetted onto one side of the product surface and distributed as evenly as possible over the entire side using a sterile plastic spreader. With minor exceptions, the inoculum volume was sufficient to cover the inoculated side of the round. The inoculated rounds were allowed to dry for $30 \mathrm{~min}$ to aid microbial attachment.

\section{Basturma-making Process}

Following inoculation, beef rounds were rubbed by gloved hand with approximately $6.0 \mathrm{~kg}$ of curing mixture per approximately $45.4 \mathrm{~kg}$ of meat. The curing mixture was provided by the cooperating commercial processor and consisted of proprietary amounts of salt, sucrose, glucose and sodium nitrite. The same batch of cure mix was used for all 18 rounds, but there was no evidence of inoculum organisms becoming concentrated in the mix and thereby increasing the inoculum level on the rounds rubbed last. After application of the curing mix, the rounds were packed into $52.1 \times 29.2 \times 20.3-\mathrm{cm}$ plastic lugs in an alternating manner with each layer of rounds perpendicular to adjacent layers. No special steps were taken to prevent round-to-round transfer of inoculum cells. Lugs were stored at $6.7 \mathrm{C}, 50 \% \mathrm{RH}$ for 7 days. After 1 week, the accumulated fluid was drained from the lugs; and the rounds were manually dry-rubbed again with a second batch of the curing mixture (industry practice) and allowed to cure for 14 more days. As with the first dry-rubbing, 
all 18 rounds were rubbed in the same batch of curing mix. The first 21 days of the process were designated as the dry-curing phase.

At the end of the dry-curing phase, the rounds were rinsed for $1 \mathrm{~h}$ with tap water (approximately 18C). To control the volume of water used during rinsing, lugs were filled with water to a level that covered the rounds. The rounds were allowed to soak for $15 \mathrm{~min}$ and then the water was drained from the lugs. This process was repeated four times in an attempt to equal the 1-h continuous rinsing used commercially. After rinsing, the rounds were hung to dry for 2 days in an environmental chamber at 24, 21 and $27 \mathrm{C}$ for trials 1,2 and 3, respectively. The three different temperatures were chosen to span typical temperatures (ambient) to which the meat was exposed at the collaborating industry partner's plant. In order to mimic diurnal changes in humidity that occurred in the commercial process, the percentage RH levels for trials 1 and 2 cycled every $12 \mathrm{~h}$ with a $65 \%$ $\mathrm{RH}$ from 8 a.m. to 8 p.m., and $80 \% \mathrm{RH}$ from 8 p.m. to 8 a.m. The RH for trial 3 was held constant at $70 \%$. During all drying periods, the rounds were hung vertically inside plastic storage containers with six evenly spaced $0.64-\mathrm{cm}$ holes drilled in each of the three sides to allow a limited amount of air circulation. Also, butcher paper was taped to the uppermost edge of the storage container to hang loosely over the open side and achieve the desired air circulation. Three rounds were hung in each container. After drying for 2 days, the rounds were pressed to remove additional moisture. In trials 1 and 2, plastic cutting boards were placed atop the rounds after these had been placed in lugs. Weights were placed atop the cutting boards to obtain pressures of $517 \mathrm{~kg} / \mathrm{m}^{2}$. In trial 3 , rounds were placed on a metal oven rack laid across several lugs to improve drainage and air circulation, and weights were placed on cutting boards atop the rounds for pressing. A pressure of $167 \mathrm{~kg} / \mathrm{m}^{2}$ was obtained. Pressing was carried out for $12 \mathrm{~h}$ at approximately $2.2 \mathrm{C}$ in an effort to duplicate characteristics of the commercial product obtained using hydraulic pressing. When pressing was complete, the rounds were rehung and allowed to dry for 4 days under the same drying conditions as previously described for each trial. Following 4 days of drying, the rounds were coated with a spice paste consisting of proprietary amounts of fenugreek, cayenne or red pepper, garlic powder, paprika and water; and these were hung to dry (same conditions as used previously in each trial) for 4 days in trial 1, 5 days in trial 2, and until an $A_{\mathrm{w}}$ level between 0.82 and 0.87 was achieved ( 6 days $)$ in trial 3 . Finished product samples were sent to a commercial testing laboratory for $A_{\mathrm{w}}$, moisture : protein ratio (MPR), $\mathrm{pH}$ and percentage water-phase salt (\%WPS) determinations (Table 1).

\section{Enumeration of Surviving Cells}

Samples were obtained after the initial application of the curing mix (day 0 ), at the end of the dry-curing phase (day 21), after pressing and rinsing (day 
TABLE 1.

WATER ACTIVITY $\left(A_{\mathrm{w}}\right)$, MOISTURE : PROTEIN RATIO

(MPR), PH AND PERCENTAGE WATER-PHASE SALT

(\%WPS) OF BASTURMA

\begin{tabular}{llllr}
\hline Trial & $A_{\mathrm{w}}$ & MPR & $\mathrm{pH}$ & $\%$ WPS \\
\hline 1 & 0.87 & $1.92: 1.00$ & 5.6 & 13.1 \\
2 & 0.95 & $2.00: 1.00$ & 6.0 & 8.3 \\
3 & 0.84 & $1.52: 1.00$ & 5.6 & 18.0 \\
\hline
\end{tabular}

23), after the first 6 days of drying ( 2 days after spice paste was applied; day 29) and at the end of the process (day 33, 34 and 35 for trials 1, 2 and 3, respectively). At each sampling time, three rounds were sampled with three individual samples being tested per round for a total of nine samples per sampling time. The individual sampling sites per round were consistent throughout the study and designated as sites A, B and C. On the inoculated side of a typical-size round, sites A, B and C were $5.1,8.9$ and $12.7 \mathrm{~cm}$, respectively, from the tip of the round. Each sample was acquired by excision, was approximately $3.8 \times 3.8 \times 0.5-\mathrm{cm}$ thick, and weighed about $10 \mathrm{~g}$. Each sample was placed in a $15 \times 23-\mathrm{cm}$ Whirl Pak filter bag (Nasco, Fort Atkinson, WI), along with $99 \mathrm{~mL}$ of BPD, and pummeled for $2 \mathrm{~min}$ at medium speed in a Stomacher 400 Circulator lab blender (Fisher Scientific). This initial dilution was arbitrarily denoted as $10^{-1}$. From the initial dilution, $1.0 \mathrm{~mL}$ was distributed for spread plating among three plates $(0.3,0.3$ and $0.4 \mathrm{~mL})$ each of MacConkey sorbitol agar (SMAC; Difco), xylose lysine desoxychlolate agar (XLD; Difco) and Listeria-selective agar base (LSA; Oxoid, Ogdensburg, NY) with added Listeria-selective supplements (Oxford formulation; Oxoid). Because the intent of this study was to evaluate the potential growth of pathogens, no attempt was made to recover and enumerate injured cells. From the original dilution and each subsequent dilution, $0.1 \mathrm{~mL}$ was spread on one SMAC, XLD and LSA plate per dilution. Plates were incubated at $35 \mathrm{C}$ and then examined for typical colonies of E. coli O157:H7 (white-colorless), Salmonella spp. (black) after $20-24 \mathrm{~h}$, and $L$. monocytogenes (grayish, small, surrounded by black precipitate) after $48 \mathrm{~h}$. For simplicity, the results were expressed as log cfu/ piece. For each sampling time, one colony of each organism was selected for confirmation testing, transferred to BHIA and incubated at 35C for $20-24 \mathrm{~h}$. Presumptive L. monocytogenes colonies were tested for Gram-stain reaction, cellular morphology, oxidase activity and biochemical characteristics (API Listeria kit, bioMérieux, Hazelwood, MO). Presumptive Salmonella spp. colonies were tested for Gram-stain reaction, cellular morphology and biochemical characteristics (API 20E kit, bioMérieux), and presumptive E. coli O157:H7 
colonies were tested for Gram-stain reaction, cellular morphology, oxidase activity and $\mathrm{O}$ antigen latex agglutination (Oxoid).

\section{Data Analysis}

Three rounds were each analyzed at three locations at each sampling time. No difference in numbers of surviving pathogens was noted between sampling sites A, B and C, so the mean log colony forming units was calculated for each round from the three sample values. A mean and standard deviation were then calculated for the three rounds at each sampling time. A value of $0.95 \mathrm{log} \mathrm{cfu} / \mathrm{g}$ ( $1 \mathrm{cfu}$ less than the 10-cfu detection limit) was assigned when no colonies were present for the least dilute plating. The two-sample $t$-test (Snedecor and Cochran 1980) was used to compare the level of a given pathogen at a given sampling time to that of the preceding sampling time within a single trial. A significance level of $5 \%(P<0.05)$ was used.

\section{RESULTS}

The techniques used in the three trials were very consistent through the dry-curing and rinsing steps. However, the range of pressing and drying conditions purposely used over the three trials resulted in different finished product MPR, \%WPS and $A_{\mathrm{w}}$ values (Table 1). In trial 2, some case-hardening occurred which may have limited moisture loss. Because of the different pressing and drying conditions, microbiological results were not compared across trials using statistical analyses. However, pathogen levels within a trial could be compared between sampling times and general trends (across trials), because the numbers of pathogens enumerated were readily apparent. Throughout all the three trials, the identity of each isolate was confirmed as that of an inoculum organism.

As seen in Table 2, there was a general reduction in pathogen numbers throughout the process. Pathogen reductions could have resulted from death and/or injury within the population because injured yet viable cells would not have been detected by plating on selective media. Through the first 21 days of processing, the reductions in log colony forming units per sample of Salmonella serovars, E. coli O157:H7 and L. monocytogenes were 2.1-3.6, 1.8-3.4 and 1.8-3.2, respectively. These decreases were usually statistically significant $(P<0.05)$. The largest decrease in numbers for each pathogen was in trial 2. Day 8 sampling data from trial 1 (not shown) suggested that the majority of the decrease in pathogen numbers occurred after the initial 8 days. There are two possible explanations for the substantially lower pathogen numbers observed at day 21. The pathogens may have died during the final 13 days of dry-curing 
TABLE 2.

LETHALITY OF THE BASTURMA-MAKING PROCESS AGAINST ESCHERICHIA COLI O157:H7, SALMONELLA SEROVARS AND LISTERIA MONOCYTOGENES

\begin{tabular}{|c|c|c|c|c|c|c|}
\hline \multirow[t]{2}{*}{ Sampling time } & \multicolumn{2}{|c|}{ E. coli $\mathrm{O} 157: \mathrm{H} 7$} & \multicolumn{2}{|c|}{ Salmonella serovars } & \multicolumn{2}{|c|}{ L. monocytogenes } \\
\hline & Mean value & Reduction & Mean value & Reduction & Mean value & Reduction \\
\hline \multicolumn{7}{|l|}{ Day 0} \\
\hline Trial 1 & $5.8(0.3)$ & - & $5.6(0.4)$ & - & $6.5(0.3)$ & - \\
\hline Trial 2 & $6.5(0.1)$ & - & $6.4(0.2)$ & - & $6.4(0.1)$ & - \\
\hline Trial 3 & $6.3(0.2)$ & - & $6.0(0.2)$ & - & $6.4(0.2)$ & - \\
\hline \multicolumn{7}{|c|}{ Day 21 (after rinse) } \\
\hline Trial 1 & $3.6(0.7)^{\mathrm{a}}$ & 2.2 & $3.5(0.6)^{\mathrm{c}}$ & 2.1 & $4.3(0.9)^{\mathrm{j}}$ & 2.2 \\
\hline Trial 2 & $3.1(0.8)^{\mathrm{g}}$ & 3.4 & $2.8(0.5)^{\mathrm{h}}$ & 3.6 & $3.2(0.7)^{\mathrm{o}}$ & 3.2 \\
\hline Trial 3 & $4.5(0.1)$ & 1.8 & $3.7(0.2)^{1}$ & 2.3 & $4.6(0.2)^{\mathrm{n}}$ & 1.8 \\
\hline \multicolumn{7}{|c|}{ Day 23 (after pressing) } \\
\hline Trial 1 & $2.5(0.8)$ & 3.3 & $2.8(0.8)^{\mathrm{d}}$ & 2.8 & $3.5(0.1)$ & 3.0 \\
\hline Trial 2 & $3.0(0.6)$ & 3.5 & $3.7(0.2)$ & 2.7 & Not tested & \\
\hline Trial 3 & $2.1(0.4)^{\mathrm{k}}$ & 4.2 & $1.4(0.3)^{\mathrm{m}}$ & 4.6 & $3.7(0.3)$ & 2.7 \\
\hline \multicolumn{7}{|c|}{ Day 29 (2 days after spice paste was applied) } \\
\hline Trial 1 & Not tested & & Not tested & & Not tested & \\
\hline Trial 2 & $1.9(0.2)$ & 4.6 & $1.7(0.4)^{\mathrm{i}}$ & 4.7 & $2.7(0.9)$ & 3.7 \\
\hline Trial 3 & $0.95 *(0)$ & 5.4 & $0.95 *(0)$ & 5.1 & $2.5(0.1)$ & 3.9 \\
\hline \multicolumn{7}{|l|}{ Finished product } \\
\hline Trial 1 & $0.95^{*}(0)^{\mathrm{b}}$ & 4.9 & $0.95^{*}(0)^{\mathrm{e}}$ & 4.7 & $2.5(0.6)^{\mathrm{f}}$ & 4.0 \\
\hline Trial 2 & $1.5(0.4)$ & 5.0 & $1.9(0)$ & 4.5 & $1.8(0.2)$ & 4.6 \\
\hline Trial 3 & $0.95 *(0)$ & 5.4 & $0.95 *(0)$ & 5.1 & $1.5(0.1)$ & 4.9 \\
\hline
\end{tabular}

Each value is the mean $\log$ cfu/piece for three tested beef rounds. Each beef round was sampled in three locations, with the mean $\log$ cfu/piece determined.

The standard deviation is shown in parentheses. Reduction in log cfu/piece was calculated by subtracting the mean $\log \mathrm{cfu} /$ piece at a given step from that determined at day 0 .

* Assigned value for log cfu/piece when no colonies were observed on least dilute plate.

$\stackrel{\mathrm{a}-\mathrm{o}}{ }$ Superscript indicates mean $\log$ cfu/piece is significantly different $(P<0.05)$ from the mean in that trial for the preceding sampling time.

or, alternatively, the pathogens may have been physically removed from the beef rounds during rinsing. Future studies should determine the mechanism by which pathogen numbers were reduced. In addition, future studies should determine the pathogen load in the rinse water. In either case, however, pathogen numbers on rinsed dry-cured beef rounds could be expected to be lower than before dry-curing began. The temperature employed during drycuring, $6.7 \mathrm{C}$, is above the minimum growth temperature for L. monocytogenes (ICMSF 1996) and slightly below the accepted minimum growth temperatures for most Salmonella serovars and E. coli O157:H7 (ICMSF 1996). It is well known, however, that the presence of growth-inhibiting environmental conditions, such as increased levels of salt and sodium nitrite, may result in the 
inability of a bacterium to grow at its normal minimum growth temperature (Mossel et al. 1995; ICMSF 1996; Davidson 2001).

Further reduction in levels of E. coli O157:H7 and Salmonella serovars occurred in the 2 days of drying and pressing that followed rinsing (Table 2). Three different sets of drying conditions were employed in this part of the process, and the pressing procedure was modified for the final trial. These variations did not have a clear effect on pathogen reductions. Compared with postrinsing values, Salmonella serovar levels decreased by an additional 0.7 and $2.3 \log$ cfu (both statistically significant) in trials 1 and 3, respectively. However, in trial 2, levels of Salmonella serovars were 0.9 log cfu higher (not statistically significant) after pressing compared with postdry-curing values. Reductions in E. coli O157:H7 levels ranged from $0.1 \log$ cfu in trial 2 (not statistically significant) to $2.4 \log$ cfu (statistically significant) in trial 3. Levels of L. monocytogenes fell by 0.8 and $0.9 \log \mathrm{cfu}$ (not statistically significant) in trials 1 and 3, respectively.

The initial 6 days of drying after pressing, with the surface application of the spice paste occurring after 4 days, resulted in further reductions in pathogen numbers. The decrease was statistically significant for salmonellae in trial 2, and levels of E. coli O157:H7 and Salmonella spp. in trial 3 fell below the detection limit. Levels of L. monocytogenes also continued to fall during this interval. The continued lethal effect of drying was evident during the final 4-6 days of drying. No detectable E. coli O157:H7 or Salmonella spp. were detected on finished products in trials 1 and 3 , and very low levels were found in trial 2. The difference in survival between trial 2 and the other trials may reflect the higher moisture content in the trial 2 finished product. Levels of $L$. monocytogenes also continued to fall during the last 4-6 days of processing, with overall reductions of 4.0-4.9 $\log$ cfu by the completion of the basturmamaking process.

\section{DISCUSSION}

Several general conclusions can be drawn from the results of the three basturma-making trials. Of the three pathogens studied, L. monocytogenes was clearly the most likely to survive the basturma-making process, although it was also clearly incapable of growth. Provided proper cooking procedures are used, this survival ability could be expected to have little bearing on consumer safety. Commercial heat-processing lethality standards set by the USDA for beef products call for heat sufficient to reduce Salmonella numbers by 6.5 or $7.0 \log$ cfu (USDA 1999b). Retail food operators have similar cooking requirements for beef (FDA 2005), and consumers are advised to cook beef products to an internal temperature of $71.1 \mathrm{C}$, which provides even greater lethality 
(USDA 2005). Heating treatments that reduce numbers of salmonellae by $7.0 \log$ cfu have been estimated to reduce L. monocytogenes numbers by $4 \mathrm{log}$ cfu (American Meat Institute Foundation 2005). Unless the finished basturma contained L. monocytogenes at levels greater than $4 \log$ cfu, or supported growth to such a level, recommended cooking procedures should dramatically decrease the risk of basturma-linked listeriosis. In addition, the low $A_{\mathrm{w}}$ values achieved in trials 1 and 3 suggest that L. monocytogenes is very unlikely to grow on finished basturma prepared using the same steps as in these trials. This reduced $A_{\mathrm{w}}$, along with the degree of lethality achieved during the basturmamaking process, suggests that basturma made as in this study presents little risk as a vehicle for foodborne listeriosis.

Previous microbiological surveys have found that Salmonella serovars, when detected, are only present at very low levels in ground beef (USDA 1996a). Quantitative data on E. coli O157:H7 in ground beef are not available. Given this finding and the low prevalence of E. coli O157:H7 and Salmonella serovars on postintervention beef carcass samples that were qualitatively tested using enrichment-based techniques (Rivera-Betancourt et al. 2004), it is highly unlikely that Salmonella serovars or E. coli O157:H7 would be present at high levels on beef rounds. Thus, our results strongly suggest that basturma prepared by dry-curing, rinsing, pressing and drying presents little risk of foodborne infection caused by these pathogens, particularly because the product is cooked prior to eating.

\section{CONCLUSION}

The results of our study highlight the potential importance of dry-curing and drying steps for pathogen reduction in meat processing. Other researchers have noted the lethality of dry-curing and drying on Enterobacteriaceae, but we are unaware of any published studies on the survival of enteric bacterial pathogens on dried dry-cured products such as basturma. Aksu and Kaya (2001) reported that levels of Enterobacteriaceae in a finished dry-cured pasturma product were below the detection limit of $100 \mathrm{cfu} / \mathrm{g}$. However, the fermentation step used in this product may have accentuated the decrease in these enteric bacteria. Samelis et al. (1998) described a similar decrease in Enterobacteriaceae during the natural (no starter culture, 7 days) fermentation and drying (3 weeks at 15-16C) of traditional Greek salami. It is notable that Listeria spp., although present in the fresh salami mix, had disappeared by the end of the process. Vilar et al. (2000) found that Enterobacteriaceae levels fell from about $4.0 \mathrm{log} \mathrm{cfu} / \mathrm{g}$ to below the detection limit after salting/dry-curing of lacón, a traditional Spanish meat product. Clearly, sequential dry-curing and drying of whole muscle products as applied in the present study is unlikely to 
allow growth of pathogenic bacteria and thus would enhance the safety of finished products prior to cooking. It is quite possible that these steps also play an important role in inhibiting pathogen growth during the processing of several dried ready-to-eat meat products that receive little or no thermal processing. Such products include cold-smoked whole-muscle beef and pork pieces and certain salami products available commercially. However, further validation would be necessary to validate scientifically the lethality of processes used in making these ready-to-eat products.

\section{ACKNOWLEDGMENT}

The authors gratefully acknowledge the processing assistance of Greg M. Burnham.

\section{REFERENCES}

ABERLE, E.D., FORREST, J.C., GERRARD, E.D. and MILLS, E.W. 2001. Principles of Meat Science, 4th Ed., Kendall/Hunt Publishing Co., Dubuque, IA.

AKSU, M.I. and KAYA, M. 2001. The effect of starter culture use in pasturma production on the properties of end product. Turk. J. Vet. Anim. Sci. 25, 847-854.

AMERICAN MEAT INSTITUTE FOUNDATION. 2005. Instructions for using the AMI process lethality determination spreadsheet http://www.amif.org/FactsandFigures/AMIF-Process-

ProcessLethality.htm\#instructions (accessed October 12, 2005).

ANONYMOUS. 2005a. Food words: A culinary glossary by BostonChefs.com. http://bostonchefs.com/glossary/ (accessed October 12, 2005).

ANONYMOUS. 2005b. Basterma, basturma, pasturma. http:// members.aol.com/ebgweb2/15Basterma.html (accessed October 12, 2005).

ANONYMOUS. 2005c. Pasturma. http://www.answers.com/topic/pastirma (accessed October 12, 2005).

DAVIDSON, P.M. 2001. Chemical preservatives and natural antimicrobial compounds. In Food Microbiology: Fundamentals and Frontiers, 2nd Ed. (M.P. Doyle, L.R. Beuchat and T.J. Montville, eds.) pp. 602-603, ASM Press, Washington, DC.

UNITED STATES FOOD AND DRUG ADMINISTRATION (FDA). 2005. Chapter 3 "Food". In 2005 Food Code. http://www.cfsan.fda.gov/ $\sim$ acrobat/fc/05-3.pdf (accessed October 12, 2005). 
INTERNATIONAL COMMISSION ON MICROBIOLOGICAL SPECIFICATIONS FOR FOODS OF THE INTERNATIONAL UNION OF BIOLOGICAL SOCIETIES (ICMSF). 1996. Microorganisms in Foods 5: Characteristics of Microbial Pathogens, pp. 129, 144, 223, Blackie Academic \& Professional, London, U.K.

JAY, J.M. 1992. Modern Food Microbiology, 4th Ed., pp. 44-45, Chapman \& Hall, New York, NY.

MOSSEL, D.A., CORRY, J.E.L., STRUIJK, C.B. and BAIRD, R.M. 1995. Essentials of the Microbiology of Foods: A Textbook for Advanced Studies, pp. 80-81, John Wiley \& Sons, New York, NY.

RIVERA-BETANCOURT, M., SHACKELFORD, S.D., ARTHUR, T.M., WESTMORELAND, K.E., BELLINGER, G., ROSSMAN, M., REAGAN, J.O. and KOOHMARAIE, M. 2004. Prevalence of Escherichia coli O157:H7, Listeria monocytogenes, and Salmonella in two geographically distant commercial beef processing plants in the United States. J. Food Prot. 67, 295-302.

SAMELIS, J., METAZOPOULOS, J., VLASSI, M. and PAPPA, A. 1998. Stability and safety of traditional Greek salami - A microbiological ecology study. Int. J. Food Microbiol. 44, 69-82.

SNEDECOR, G.W. and COCHRAN, W.G. 1980. Statistical Methods, 7th Ed., pp. 91-93, The Iowa State University Press, Ames, IA.

UNITED STATES DEPARTMENT OF AGRICULTURE, FOOD SAFETY AND INSPECTION SERVICE, SCIENCE \& TECHNOLOGY, MICROBIOLOGY DIVISION (USDA). 1996a. Nationwide federal plant raw ground beef microbiological survey, August 1993-March 1994. http:// www.fsis.usda.gov/OPHS/baseline/rwgrbeef.pdf (accessed March 29, 2005).

UNITED STATES DEPARTMENT OF AGRICULTURE, FOOD SAFETY AND INSPECTION SERVICE (USDA). 1996b. Pathogen reduction; hazard analysis and critical control point (HACCP) systems: Final rule. Fed. Regist. 61, 38805-38855.

UNITED STATES DEPARTMENT OF AGRICULTURE, FOOD SAFETY AND INSPECTION SERVICE (USDA). 1997. Guidebook for the preparation of HACCP plans. http://haccpalliance.org/alliance/haccpmodels/ guidebook.pdf (accessed October 12, 2005).

UNITED STATES DEPARTMENT OF AGRICULTURE, FOOD SAFETY AND INSPECTION SERVICE (USDA). 1999a. Generic HACCP model for raw, not ground meat and poultry products. http://www.fsis.usda.gov/ OPPDE/nis/outreach/models/HACCP-4.pdf (accessed October 12, 2005).

UNITED STATES DEPARTMENT OF AGRICULTURE, FOOD SAFETY AND INSPECTION SERVICE (USDA). 1999b. Compliance guidelines 
for meeting lethality performance standards for certain meat and poultry products: Appendix A. http://www.fsis.usda.gov/oa/fr/95033f-a.htm (accessed October 12, 2005).

UNITED STATES DEPARTMENT OF AGRICULTURE, FOOD SAFETY AND INSPECTION SERVICE (USDA). 2004. Compliance guidelines to control Listeria monocytogenes in post-lethality exposed ready-to-eat meat and poultry products. http://www.fsis.usda.gov/OPPDE/rdad/ FRPubs/97-013F/CompGuidelines.pdf (accessed April 19, 2004).

UNITED STATES DEPARTMENT OF AGRICULTURE, FOOD SAFETY AND INSPECTION SERVICE (USDA). 2005. Use a food thermometer. http://www.fsis.usda.gov/Frame/FrameRedirect.asp?main+/oa/thermy/ bro_text.htm (accessed October 12, 2005).

VILAR, I., GARCIA-FONTAN, M.C., PRIETO, B., TORNADIJO, M.E. and CARBALLO, J. 2000. A survey on the microbiological changes during the manufacture of dry-cured lacón, a Spanish traditional meat product. J. Appl. Microbiol. 89, 1018-1026. 